\title{
SIFAT FISIK BATANG DAN CABANG KAYU MAKADAMIA
}

\author{
Stem and Branch Physical Properties of Macadamia Wood
}

\author{
Andi Detti Yunianti
}

\begin{abstract}
Since there have been a big difference between wood production and industrial need, wood diversification plays an important role in handling wood deficiencies. Wood raw material diversification could developed and increased throughout the use of whole parts of the tree including branch. The current study was aimed at understanding stem and branch physical properties (basic density, air-dry specific gravity, air-dry moisture content and shrinkage) of macadamia wood as quality indicators for efficient utilization in the future. For the purpose of the study, parts of stem and branch of the tree were taken from a macadamia tree. Test specimens of stem were cut $50 \mathrm{~cm}$ from the ground while that of branch were selected from the largest diameter at $10 \mathrm{~cm}$ distance from the main stem of the tree. All samples were tested for their physical properties according to ISO standards, 1975. Results showed that the basic density, air dry specific gravity and longitudinal shrinkage of the branchwood of macadamia were higher than those of the stem. The air-dry moisture content, radial and tangential shrinkage were low on the branchwood.
\end{abstract}

Keywords : Wood Physical Properties, Branchwood, Macadamia Wood

\section{PENDAHULUAN}

Potensi kayu bulat yang digunakan sebagai bahan baku industri makin terbatas jumlahnya. Hal ini dapat dilihat dari kebutuhan kayu bulat saat ini yang berkisar $20-30$ juta $\mathrm{m}^{3}$ sementara produksinya dalam tahun 2003 hanya mencapai 10,09 juta $\mathrm{m}^{3}$ (Departemen Kehutanan, 2004). Salah satu cara mengatasi kesenjangan tersebut adalah perlu adanya diversifikasi bahan baku yaitu pengembangan jenis andalan yang mempunyai prospek untuk dikembangkan dan peningkatan penggunaan bagian pohon yang tak terperdagangkan (unmerchantable tree) untuk memaksimumkan penggunaan seluruh bagian kayu dari pohon.

Di Sulawesi terdapat sekitar 936 jenis pohon meliputi 405 marga, 84 suku dan 754 jenis di antaranya telah diketahui nama botaninya. Salah satunya adalah kayu makadamia (Macadamia hildenbrandii Steen) yang lebih dikenal dengan nama lokal kayu kates (Luwuk Banggai, Sulawesi Tengah) atau tomaku (Mamasa, Sulawesi Barat). Jenis ini merupakan endemik karena daerah persebaran alaminya hanya di Sulawesi (Wardani, dkk., 2004) dan telah dicoba sebagai jenis kayu reboisasi di hulu Sub DAS Mamasa (Ginoga, dkk, 1987). Sifat kayu ini terutama yang ada di Luwuk Banggai belum banyak diketahui dan hanya dimanfaatkan sebagai bahan baku mebel dan kayu bakar.

Pemilihan dan penggunaan kayu untuk suatu tujuan pemakaian memerlukan pengetahuan tentang sifat dasar kayu, terutama sifat fisik. Sifat fisik paling sering digunakan sebagai indikator kualitas kayu karena sifat fisik sangat mudah diukur dan banyak kaitannya dengan hasil atau substansi kayu yang ada dalam volume tertentu dan kualitas akhir produk (Zobel dan Talbert, 1984). Penggunaan kayu tidak terbatas pada bagian batang tetapi juga bagian cabang yang dapat dijadikan bahan baku, meskipun penggunaannya tidak sebanyak bagian batang. Pengetahuan sifat fisik bagian batang dan cabang sangat diperlukan untuk meningkatkan penggunaan kayu makadamia yang ada di Kab. Luwuk Banggai, bukan hanya terbatas pada mebel dan kayu bakar tetapi penggunaan yang lebih banyak dan bervariasi.

\section{BAHAN DAN METODE}

Bahan yang digunakan pada penelitian ini adalah kayu makadamia yang berasal dari Kab. Luwuk Banggai, Provinsi Sulawesi Tengah. Bagian pohon yang dijadikan sampel penelitian adalah batang dan cabang. Bagian batang diambil $50 \mathrm{~cm}$ dari permukaan tanah dan bagian cabang diambil 
diameter terbesar dengan jarak $10 \mathrm{~cm}$ dari batang. Dari masing-masing bagian diambil lempengan tipis $(5 \mathrm{~cm})$ kemudian dibuat contoh uji dari empulur ke arah kulit.

Sifat fisik yang diuji adalah berat jenis, kerapatan, kadar air dan penyusutan. Ukuran contoh uji dan prosedur pengujian menggunakan standar ISO, 3130 - 31, 1975 (Prayitno, 1995). Pengujian persentase kadar air dilakukan pada kondisi kering udara dan dihitung sebagai perbandingan antara selisih berat kering udara dan berat kering tanur dengan berat kering tanur. Berat jenis ditentukan pada kondisi kering udara dan dihitung sebagai perbandingan berat kering tanur dengan volume kering udara. Kerapatan dasar dihitung berdasarkan perbandingan berat kering tanur dengan volume basah. Persentase penyusutan dihitung dari kondisi basah ke kering tanur berdasarkan perbandingan antara pengurangan dimensi dengan dimensi basah.

\section{HASIL DAN PEMBAHASAN}

Hasil perhitungan berat jenis, kerapatan dan kadar air batang dan cabang kayu makadamia disajikan pada Gambar 1, 2 dan 3. Berat jenis kering udara dan kerapatan dasar cabang lebih tinggi daripada batang dan masing masing cenderung meningkat dari empulur ke arah kulit. (Gambar 1 dan 2). Menurut Haygreen dan Bowyer (1989); Tsoumis (1991), cabang umumnya mempunyai kerapatan yang lebih tinggi dibandingkan dengan batang. Faktor yang mempengaruhi perbedaan ini adalah lingkaran tahun pada cabang yang sempit karena pertumbuhan cabang yang lebih lambat dari batang. Di samping itu, beberapa jenis sel lebih banyak terdapat pada cabang daripada batang, misalnya jari-jari dan pembuluh dengan jumlah serat yang lebih sedikit dan adanya kayu reaksi. Kecenderungan berat jenis dan kerapatan yang meningkat dari empulur ke kulit disebabkan karena tingginya proporsi kayu akhir dan umur (Tsoumis, 1991).

Berat jenis kering udara pada penelitian ini berkisar 0,56 sampai 0,59 dengan rata-rata 0,58 pada bagian batang dan 0,62 sampai 0,72 dengan rata-rata 0,66 pada bagian cabang. Jika dibandingkan dengan hasil penelitian Ginoga, dkk (1987) yang menunjukkan berat jenis kering udara berkisar $0,52-0,60$ dengan rata-rata 0,54 , nilai berat jenis kering udara pada batang yang diperoleh pada penelitian ini lebih rendah. Hal ini antara lain bisa disebabkan oleh umur pohon dan asal tempat tumbuhnya.

Kadar air cabang lebih rendah daripada batang dan cenderung meningkat dari empulur ke arah kulit pada batang dan cenderung konstan pada cabang (Gambar 3). Hal ini sejalan dengan penelitian Yunianti (2000), yang menyatakan kadar air cabang kayu Acacia mangium lebih rendah daripada batang.

Kadar air kering udara pada penelitian ini berkisar 10,41 \% sampai 12,96 dengan rata-rata $11,84 \%$ pada bagian batang dan 9,59 \% sampai $10,41 \%$ dengan rata-rata 10,15 pada bagian cabang. Jika dibandingkan dengan hasil penelitian Ginoga, dkk (1987), yang menunjukkan nilai kadar air kering udara berkisar 14,20 \% sampai 15,00 \% dengan rata-rata $14,50 \%$, nilai kadar air kering udara pada batang yang diperoleh pada penelitian ini lebih rendah.

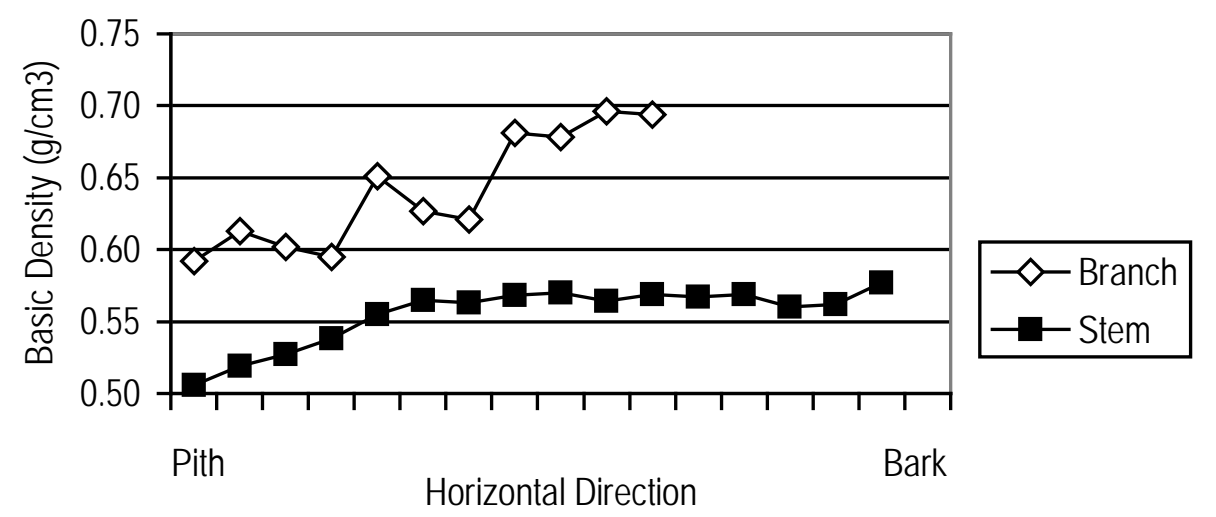

Figure 1. Basic density of stem and branch 


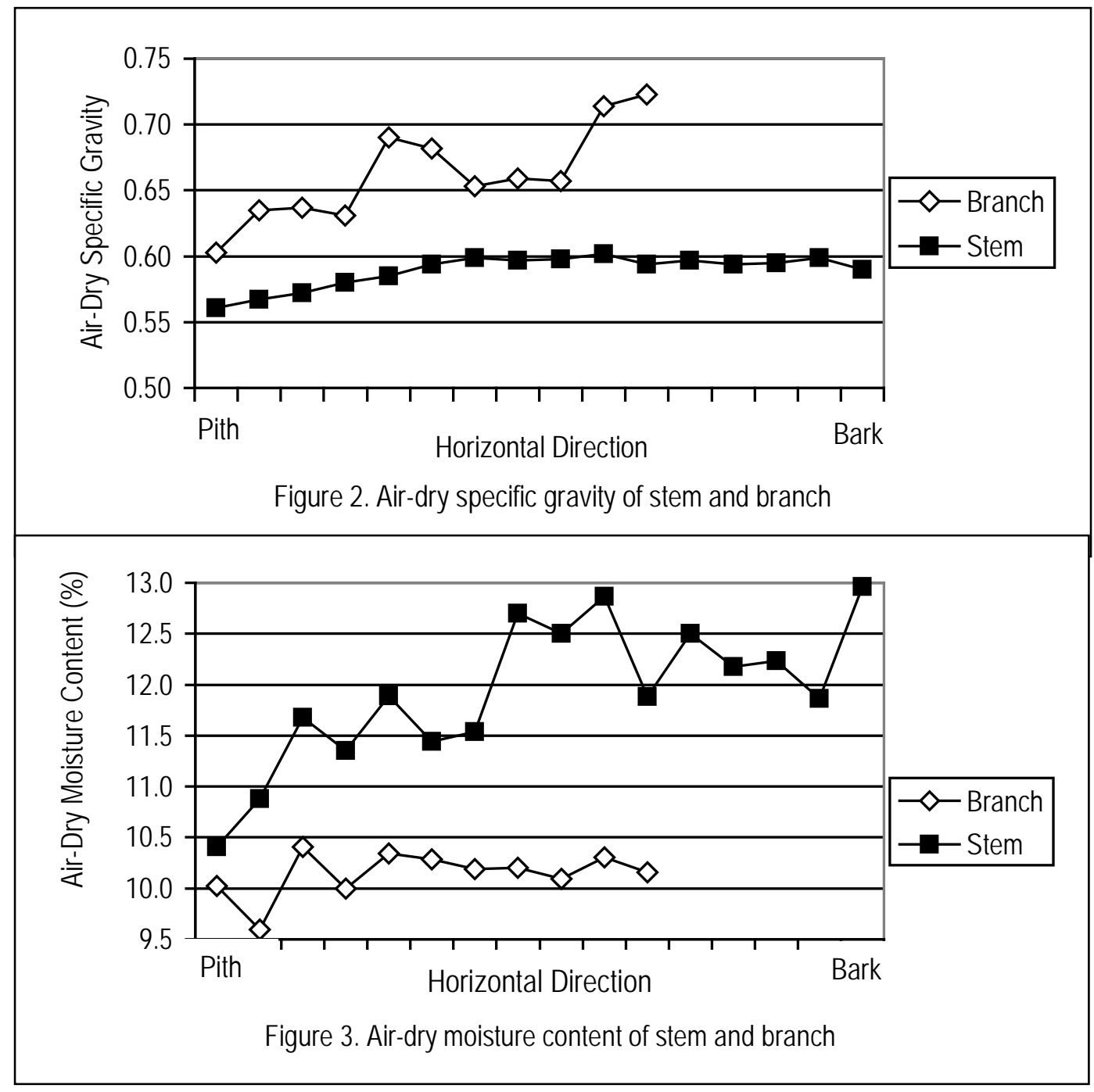

Penyusutan arah longitudinal, radial dan tangensial kayu makadamia masing-masing seperti disajikan pada Gambar 4, 5 dan 6. Penyusutan bagian batang kayu makadamia dari kondisi basah ke kering tanur pada arah longitudinal adalah sebesar $0,96 \%$. Nilai ini hampir sama dengan penyusutan arah longitudinal bagian cabang $(0,93$ $\%)$. Rata-rata penyusutan batang arah tangensial $(8,26 \%)$ dan arah radial $(5,92 \%)$ lebih rendah dibanding besarnya penyusutan arah tangensial $(10,40 \%)$ dan arah radial $(6,28 \%)$ dari bagian cabang. Nilai penyusutan batang dari hasil penelitian ini lebih tinggi daripada yang telah dilakukan oleh Ginoga, dkk (1987) yaitu rata-rata penyusutan $7,89 \%(\mathrm{~T})$ dan $2,42 \%$ (R). Rendahnya penyusutan dalam arah radial tersebut dapat disebabkan oleh jari-jari kayu makadamia yang tergolong lebar. Jari-jari lebar dan relatif berdinding tipis dapat menahan perubahan dimensi dalam arah radial (Panshin and de Zeeuw, 1980).
Penyusutan transversal kayu makadamia cenderung meningkat dari empulur ke kulit. Menurut Panshin and de Zeeuw (1980), kerapatan yang semakin meningkat menyebabkan penyusutan yang semakin besar dan hal ini sejalan dengan pola kerapatan yang meningkat (Gambar 1) dengan penyusutan yang semakin meningkat dari empulur ke kulit (Gambar 5 dan 6). Nilai ratio penyusutan tangensial terhadap radial batang kayu makadamia pada bagian batang adalah 1,39 dan bagian cabang 1,65, lebih kecil dari nilai $T / R$ hasil penelitian oleh Ginoga, dkk (1987) yaitu 3,20. Hal ini menunjukkan kayu makadamia yang berasal dari Kab. Luwuk Banggai mempunyai kestabilan dimensi yang sedang. Dimensi kayu dikatakan stabil jika nilai T/R lebih kecil dari 2 dengan angka penyusutan tangensial dan radial yang rendah. 


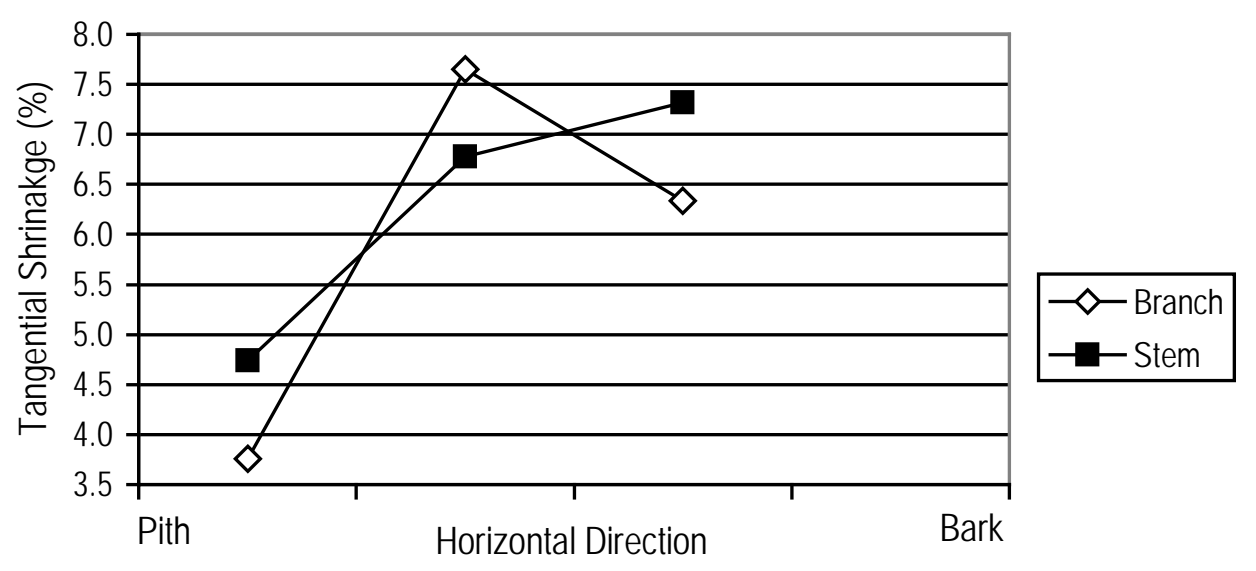

Figure 4. Tangential shrinkage of stem and branch

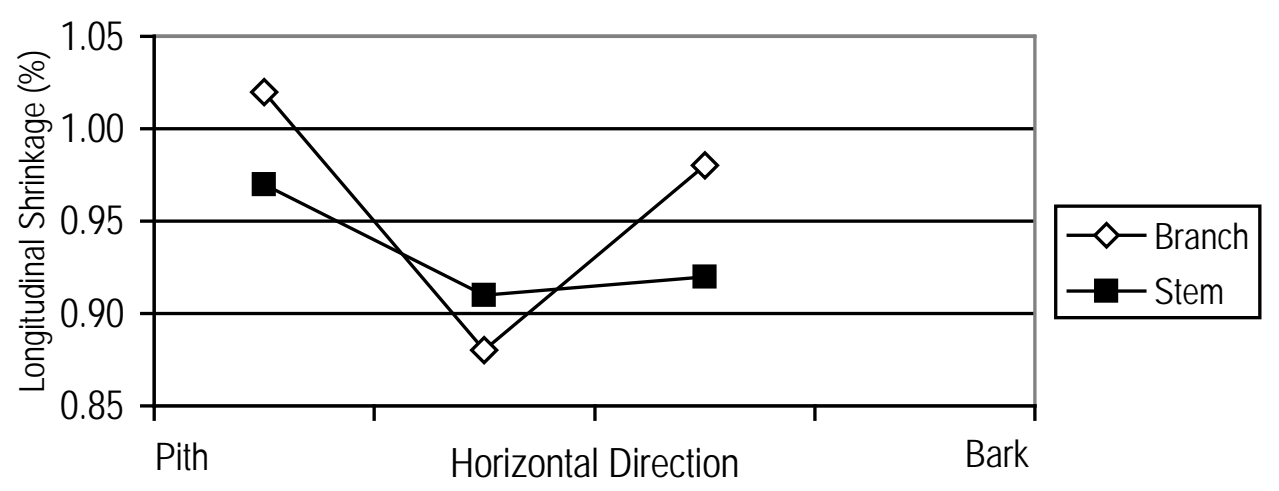

Figure 5. Longitudinal shrinkage of stem and branch

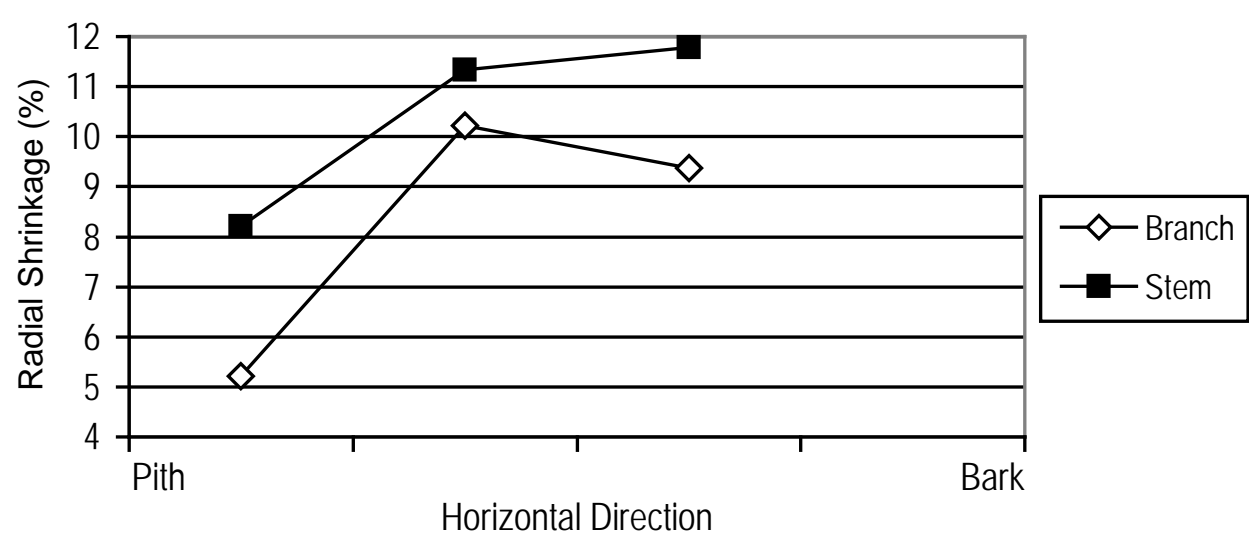

Figure 6. Radial shrinkage of stem and branch

Hasil penelitian menunjukkan bahwa sifat fisik kayu makadamia pada bagian batang dan cabang berbeda, sehingga untuk memaksimalkan penggunaan kayu makadamia di lapangan perlu dikombinasikan yaitu bagian batang dapat dijadikan bahan baku mebel seperti yang telah 
dilakukan oleh masyarakat saat ini dan bagian limbah kayunya terutama bagian cabang dapat digunakan sebagai bahan baku industri papan serat dan papan partikel. Hal ini dikarenakan bagian cabang mempunyai kerapatan dan berat jenis yang tinggi (tanpa mengabaikan sifat-sifat dasar lainnya). Sifat papan partikel yaitu kekuatan tarik tegak lurus permukaan dan kekuatan tekan menurun, penyerapan air dan pengembangan tebal meningkat dengan meningkatnya berat jenis kayu. Rendemen pulp meningkat dengan meningkatnya berat jenis kayu yang dapat digunakan sabagai bahan baku papan serat.

\section{KESIMPULAN}

1. Berat jenis dan kerapatan cabang lebih tinggi daripada batang kayu makadamia.

2. Kadar air kering udara dan penyusutan arah transversal cabang lebih rendah daripada batang kayu makadamia.

\section{DAFTAR PUSTAKA}

Departemen Kehutanan. 2004. Statistik kehutanan Indonesia. 2003. Ditjen Bina Produksi Kehutanan. Jakarta.
Ginoga, B., D. Seran., M. Lempang., dan M. K..Allo. 1987. Pertumbuhan dan sifat kayu Tomaku (Macadamia hildebrandii V,St.). Jurnal Penelitian Kehutanan Vol.I, No. 1 Juli. Pp. 2-5.

Haygreen, J.G., dan J.L. Bowyer. 1989. Hasil hutan dan ilmu kayu. Suatu pengantar. Diterjemahkan oleh S.A.. Hadikusuma. Gadjah Mada University Press. Yogyakarta.

Panshin, A.J. dan C. de Zeeuw. 1980. Textbook of wood technology. Fourth edition. Mc. Graw-Hill Book Co. New York.

Prayitno, T.A. 1995. Pengujian sifat fisika dan mekanika. menurut ISO. Fakultas Kehutanan. Universitas Gadjah Mada. Yogyakarta.

Tsoumis, G. 1991. Science and technology of wood: structure, properties, utilization. Van Nostrand Reinhold. New York.

Wardani, M., N. Hadjib, dan P. Sutigno. 2004. Prioritas jenis andalan setempat Sulawesi. Prosiding Seminar Mapeki VII. 5 - 6 Agustus Makassar. D 16.

Yunianti, A.D., 2000. Pengaruh penjarangan terhadap kualitas kayu Acacia mangium. Tesis Program Pascasarjana Universitas Gadjah Mada. Yogyakarta. (tidak dipublikasikan)

Zobel, B.J. dan J. Talbert, 1984. Applied forest tree improvement. John Wiley \& Sons Inc. New York.

Diterima : 31 Desember 2005

\section{Andi Detti Yunianti}

Lab. Teknologi Hasil Hutan, Jurusan Kehutanan, Universitas Hasanuddin Kampus Tamalanrea, Jl. Perintis Kemerdekaan Km. 10, Makassar 90245

Telp./Fax. 0411-585917. Indonesia 